\title{
PAPERS
}

\section{A review of the use of corticosteroids in the management of pulmonary injuries and insults}

\section{ROBERTSON}

Department of Accident and Emergency Medicine, Royal Infirmary, Edinburgh, Scotland

Despite the multitude of types of insult and injury that can occur to the lungs, their response both macro- and microscopically is uniform, although the time-course for the sequence of events varies with the severity and duration of the primary stimulus.

In 1968, it was noted that during membrane haemodialysis, transient neutropenia occurred and the neutrophils were found sequestered within the pulmonary microcirculation (Kaplow \& Goffinet, 1968). Further investigation indicated that complement activation, and in particular the generation of C5a, causes leucocyte aggregation in the lung (Jacob et al., 1980). Platelets and neutrophils then produce a secondary injury as the result of release of vaso-active substances and toxic oxygen radicals (Hechtman et al., 1978; Demling et al., 1980). The neutrophils then produce proteases which destroy structural lung proteins such as collagen, elastin and fibronectin which order the interstitial cell framework of the lung (Janoff et al., 1979; McDonald et al., 1979). The normal pulmonary defence enzymes such as alphaantitrypsin have been shown to be inactivated in the presence of super-oxide radicals and oxygen, while circulating Hageman factor, fibrinogen and complement promote further local inflammatory changes.

Although Type I alveolar cells are the least numerous of the lung cell types, they cover $95 \%$ of the interalveolar septae and as a consequence of their large surface area are extremely susceptible to air- or blood-borne insults. To compound this susceptibility, Type I cells are incapable of division (Scadding \& Cumming, 1981). The larger Type II pneumocytes, which normally secrete surfactant, are, however, less susceptible to injury and proliferate as a consequence of Type I cell necrosis. They temporarily repopulate the damaged alveolar walls and later transform to functional gas-exchanging Type I cells. However, before this transformation occurs, the alveolar septae are thickened and the development of fibrosis is manifest, with disruption of normal cell

Correspondence: Dr C. Robertson, Department of Accident and Emergency Medicine, Royal Infirmary, Lauriston Place, Edinburgh, EH3 $9 Y \mathrm{~W}$, Scotland 
relationships and channels of communication between epidermal and endothelial cell and supporting interstitial cells (Rinaldo \& Rogers, 1982).

These processes have been established as developing after various lung insults, an their elucidation has suggested that for the first time specific therapy may be able tक्ष prevent the cascade of events with its formidable clinical sequelae. For almost 30 years: corticosteroids have been thought to offer a key to this problem. They have been shown to inhibit complement-induced leucocyte aggregation (Hammerschmidt et al., 1979) and to block the increase in microvascular permeability following a variety of insults in

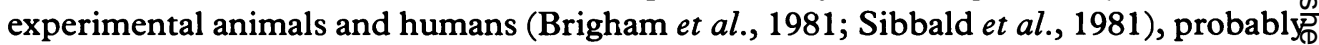
as the result of inhibiting super-oxide radical release (Bihan \& Tinker, 1982) Stabilization of cell and lysosomal membranes also occurs and some reports show improved pulmonary circulatory flow related to a fall in pulmonary venous resistance (Lucas \& Ledgerwood, 1981; Svennevig et al., 1980; Dietzman \& Lillehei, 1968). Ther follows an examination of some common clinical situations for which the use of steroids্ remains in contention.

In 1964, Hamelberg induced aspiration pneumonitis in dogs using sterile gastric juice्र introduced into the lungs via an endotracheal tube. Hydrocortisone was given to oneु group of animals, and with respect to a control group, chest radiographs showed a mores rapid improvement (Hamelberg \& Bosomworth, 1964). The number of animals in this study was small and the end-points somewhat hazy, but further investigators wer prompted to repeat similar experiments under more controlled conditions. Downs and his co-workers administered $0.1 \mathrm{~N}$ hydrochloric acid ( $\mathrm{pH} 1.0$ ) to spontaneously $\overrightarrow{0}$ breathing dogs and found the response unaltered by methyprednisolone gin pharmacological dosage (Downs et al., 1974). The mortality in the study was $80 \%$ a criticism was made that perhaps too severe an insult had been administered; therefore experiment was repeated, this time instituting controlled positive pressure ventilation the mortality in both control and steroid-treated groups dropped to $60 \%$ but there wa政 again no difference in the clinical course of either group (Chapman et al., 1974a) Generally, these results have been confirmed in a variety of animals (Chapman et al. $\frac{O}{3}$ 1974b; Dudley \& Marshall, 1974) and in the few studies involving humans. In particular, Wolfe's carefully controlled study showed no difference in mortalit $\vec{y}$. between patients treated with or without steroids, but noted an increase in bacteria $\frac{\mathbb{P}}{3}$ lung infections in the steroid-treated group (Wolfe et al., 1977).

Because of the clinical and pathological similarities between aspiration syndrome and near-drowing, Sladen gave seven such patients methylprednisolone $(5 \mathrm{mg} / \mathrm{kg}$ peô $24 \mathrm{hrs}$ i.v.) (none died) and compared them with three patients who were not given steroid, one of whom died (Sladen \& Zauder, 1971). Modell has reported his experience for the utilization of steroid therapy with an animal model (Calderwood et al., 1975) $\frac{D}{0}$ and showed no improvement in survival or arterial oxygen saturation in 80 dogs subjected to freshwater near-drowning. His study in 1976 of 91 consecutive near? drowning victims (Modell et al., 1976) was retrospective and uncontrolled but of 380 patients who were not given steroids two died (5\%) while of 52 patients given steroids eight died $(15 \%)$. Steroids used included 'methylprednisolone, dexamethasone, prednisolone and hydrocortisone in doses ranging from therapeutic to pharmacologic' While acknowledging that this study was not designed to test the efficacy of steroid? therapy the conclusions of the workers were that neither steroids, nor prophylactict antibiotics, were of any clinical value in this situation. 
The other common case of exogenous lung injury is smoke inhalation. There is relatively little experimental work to suggest the advantageous use of steroids in this situation. Dressler subjected rats to white pine smoke and his results appeared to show a beneficial effect, as measured by a reduction in interstitial oedema, in methylprednisolone treated animals but his results are somewhat difficult to interpret when one considers that the control mortality varied between $34 \%$ and $68 \%$ (Dressler et al., 1976).

Beeley indicated that in rabbits exposed to Acreolein at 376 parts per million for 15 minutes, a placebo group showed a significantly increased mortality when compared to steroid-treated animals either given as a single dose or 12 hourly (Beeley et al., 1982); however, the number of animals involved in this study was small, the histological damage was similar in all three groups, and all the animals were sacrificed at three days so that full assessment of mortality was invalid. A study performed by Welch (1977) used goats exposed to nitrogen tetroxide and showed no beneficial effect from the use of steroids on acute pulmonary dysfunction and indeed suggested that small airway obstruction in the early phases of injury was worse in the steroid-treated group.

The best human study has been performed by Moylan, who studied 26 patients all with objective bronchoscopic evidence of inhalational injury in a double blind study using methylprednisolone in a pharmacological dose $(30 \mathrm{mg} / \mathrm{kg}$ IV stat, then $30 \mathrm{mg} / \mathrm{kg}$ qid for $48 \mathrm{hrs}$ ) as an initial intravenous bolus and then 6 hourly for 2 days. The mortality for the steroid-treated groups was $53 \%$ and in the control group $30 \%$. The steroid group had nearly three times the incidence of infective complications either as pneumonias or bacteraemias (Moylan \& Chan, 1978).

A number of studies have shown an inhibitory effect for various steroids on intracellular killing, phagocytic bacteriocidal activity by neutrophils and also a reduction in the bacteriocidal activity of monocytes (Fuenfer et al., 1975; Rinehart et al., 1974). In a study giving normal and burned rats pseudomonas organisms by aerosol, steroid treatment resulted in a depressed ability of the lungs to clear bacteria related to a reduction in the migration of macrophages within the lung (Skormit \& Dressler, 1974). Indeed, alveolar macrophages were eliminated from the lung within 12 hours of steroid administration and since the re-supply time for these cells is between 36 and 48 hours it would be anticipated that further steroid administration would keep their levels low. The mechanism for the post-steroid suppression of intracellular killing of neutrophils is thought to be related to inhibition of NADH oxidase which is essential for the production of hydrogen peroxide, the primary agent responsible for bacterial killing (Fuenfer et al., 1975; Yielding \& Tomkins, 1959). A combination of these factors may thus explain the increase in late pulmonary infective complications in steroid-treated groups (see above).

In the late 1960s anecdotal reports suggested that steroids might benefit the clinical course of patients who had sustained pulmonary contusion as a consequence of blunt chest injury (De Muth \& Smith, 1965; Fulton et al., 1970). Subsequent animal studies showed a diversity of opinion with regard to the efficacy of steroids in this situation; some studies showed that the effect depended upon the nature of the steroid given while others indicated that the relationship depended upon the dosage (Shephard et al., 1969; Trinkle et al., 1975; Frantz et al., 1974). Frantz in 1974, using an experimental model, was able to cause a reproducible focal concussive lesion and in animals treated with methylprednisolone showed a dramatic reduction in the volume of contused lung in 
comparison with control groups, although within the affected areas there were non pathological differences. The effects were attributed to a reduction in pulmonaryo vascular resistance (Frantz et al., 1974). Trinkle et al. (1975) reported on patients whơ had sustained direct chest injury and his results appeared to indicate a marked benefito from the use of steroid as evidenced by the reduction in the length of intensive care and hospital stay, and also infective complications and mortality. However, although his two groups of patients were comparable with respect to their injury, the treatments giver were completely different, not only with respect to the administration of steroids bu施 also with relation to ventilation, fluid requirements, diuretics and intercostal nerve् blocks. Svennevig's study in 1980 compared 20 patients with pulmonary contusion, alf of whom received standard treatment with randomization into steroid and non-steroid groups. No patient died in either group but there appeared to be a shorter period of hospitalization, requirement for ventilation and less infective complications in the steroid-treated group (Svennevig et al., 1980). Evidence from large numbers of patients with this condition has yet to be reported, although Lucas in 1984 could find no. pulmonary benefit from the use of steroids in patients who had sustained blunt injurie to chest and other body regions (Lucas \& Ledgerwood, 1984).

In early retrospective reports during the 1960s and early 1970s the use of steroids ine fat embolism syndrome indicated that there may be some pulmonary benefit obtained(Ashbaugh \& Petty, 1966; Fischer et al., 1971).

In the 1970s a number of animal studies were performed administering oleic acid to simulate the effects of fat embolism and a number of workers suggested that there was $\overrightarrow{0}$ better ventilation/perfusion matching together with improved cardiac output affor improved oxygenation when such animals were given steroids (Hofman \& Ehrhast: 1981; Bradley et al., 1972; Kreis et al., 1973). Some workers have reported a reductiân in pulmonary oedema in such dogs treated with methylprednisolone and it has beeno postulated that the benefits have been related to a reduction in pulmonary venouso resistance and possibly also due to the improved proliferation and maturation of Type II pneumocytes (Jones \& King, 1975; Cheney et al., 1979). Stoltenberg in 19793 randomized 64 patients with lower limb fractures into placebo, steroid and hypertonice glucose treatment groups. In patients treated with methylprednisolone (1 g. methylprednisolone I.V. given on admission and repeated at 8 and $16 \mathrm{hrs}$ ) there was ang improvement in arterial oxygenation and no patient in this treatment group developed fat embolism syndrome, while three patients in the placebo group and two patients in? the hypertonic glucose group developed the syndrome. However, numbers were suchp that the difference in mortality was not statistically significant (Stoltenberg \& Gustilo, 1979). Schonfield et al. (1983), in a prospective randomized double blind study of high-? risk patients, showed a significant difference in the incidence of fat embolism syndromes in steroid-treated patients (dose $7.5 \mathrm{mg} / \mathrm{kg}$ every $6 \mathrm{hrs}$ for 12 doses). They were unable to find any complications related to steroid treatment and suggest that prophylactico corticosteroid treatment is indicated in patients at high risk of the syndrome.

Current ideas on the pathogenesis of the fat embolism syndrome postulate thew liberation of neutral fat globules from bone marrow following injury, followed by filtration in the pulmonary microcirculation. This embolization is usually asymptomatio but is followed by the direct action of lung lipoprotein lipases which hydrolize neutrap? triglycerides to glycerol and highly toxic free fatty acids. This process takes $24-27$ hourst 
and explains the latent period before full development of the so-called fat embolism syndrome (Herndon et al., 1971). Thus, the administration of steroids to such patients is to pre-treat the condition, as in the majority of cases this administration is before the full action of the lipases occurs. Further work is urgently required to identify those patients at high risk of the syndrome to allow such prophylaxis, as at present the blind administration of such potent agents cannot be wholeheartedly recommended.

Despite the many theoretical attractions for the use of steroids in many forms of chest injury and insult, there are as yet few definite situations where their use can be unreservedly recommended. Certainly, at present the weight of evidence suggests that for smoke inhalation, aspiration and near-drowning, steroids cause more harm than good. With regard to blunt chest injury and fat embolism syndrome, more promise is shown, but considerably more prospective work will be required before the routine early use of steroids can be advocated.

\section{REFERENCES}

Ashbaugh D. G. \& Petty T. L. (1966) The use of corticosteroids in the treatment of respiratory failure associated with massive fat embolism. Surgery, Gynecology and Obstetrics 123, 493-500.

Beeley J. M. et al. (1982) Treatment of inhalation damage to the lungs with corticosteroids. American Review of Respiratory Diseases 125, 156 (abstr.).

Bihan D. J. \& Tinker J. (1982) Steroids in intensive care. British fournal of Hospital Medicine 28, 323-30.

Bradley C. E., Vracko R. \& Sullivan K. N. (1972) Corticosteroids as treatment for chemical pneumonitis induced by oleic acid. Clinical Orthopaedics 86, 230-6.

Brigham K. L., Bowers R. E. \& McKeen C. R. (1981) Methylprednisolone prevention of increased lung vascular permeability following endotoxaemia in sheep. fournal of Clinical Investigation 67, 1103-10.

Calderwood H. W., Modell J. W. \& Rinz B. C. (1975) The ineffectiveness of steroid therapy for treatment of freshwater near-drowning. Anaesthesiology 43, 642-50.

Chapman R. L., Downs J. B. \& Modell J. H. (1974a) The ineffectiveness of steroid therapy in the treatment of aspiration of hydrochloric acid. Archives of Surgery 108, 858-61.

Chapman R. L., Modell J. H. \& Rinz B. C. (1974b) The effect of continuous positive pressure ventilation and steroids on aspiration of $\mathrm{HCl}$. (pH 1.8) in dogs. Anesthesia and Analgesia 53, 556-62.

Cheney F. W., Huang T. H. \& Gronka R. (1979) Effects of Methylprednisolone on experimental pulmonary injury. Annals of Surgery 190, 236-42.

Demling R. H., Proctor R., Dry N. et al. (1980) Lung lysosomal enzyme release during haemorrhagic shock and endotoxaemia. Fournal of Surgical Research 28, 269-70.

De Muth W. E. \& Smith J. M. (1965) Pulmonary contusion. American fournal of Surgery 109, 819-23.

Dietzman R. H. \& Lillehei R. C. (1968) The use of corticosteroids in the treatment of cardiogenic shock. American Heart fournal 75, 274-77.

Downs J. B., Chapman R. L. \& Modell J. H. (1974) An evaluation of steroid therapy in aspiration pneumonitis. Anesthesiology 40, 129-35.

Dressler D. P., Skormit W. A. \& Kupersmith S. (1976) Corticosteroid therapy of experimental smoke inhalation. Annals of Surgery 183, 46-52.

Dudley W. R. \& Marshall B. E. (1974) Steroid therapy for acid aspiration pneumonitis. Anaesthesiology 40, $136-41$.

Fischer J. E., Taylor R. H., Herndon J. H. \& Riseborough E. J. (1971) Massive steroid therapy in severe fat embolism. Surgery, Gynecology and Obstetrics 132, 667-72.

Frantz J. L., Richardson J. D., Grover F. L. \& Trinkle J. K. (1974) Effect of Methylprednisolone sodium succinate on experimental pulmonary contusion. Fournal of Thoracic and Cardiovascular Surgery 68, 842-4.

Fuenfer M. M., Olson G. E. \& Polk H. C. (1975) Effect of various corticosteroids upon the phagocytic bactericidal activity of neutrophils. Surgery 78, 27-33. 
Fulton R. L., Peter E. T. \& Wilson J. M. (1970) The pathophysiology and treatment of pulmonary contusion fournal of Trauma 10, 719.

Hamelberg W. \& Bosomworth P. P. (1964) Aspiration pneumonitis: experimental studies and clinicad observations. Anesthesia and Analgesia 43, 669-77.

Hammerschmidt D. E., White J. G., Craddock R. R. \& Jacob H. S. (1979) Corticosteroids inhibi两 complement-induced granulocyte aggregation. Fournal of Clinical Investigation 63, 798-803.

Hechtman H. B., Lorergan E. A., Staunton P. B. et al. (1978) Pulmonary entrapment of platelets during acut $\overrightarrow{\vec{\partial}}$ respiratory failure. Surgery $83,277-83$.

Herndon J. H., Riseborough E. J. \& Fischer J. J. (1979) Fat embolism: a review of current concepts. fourna of Trauma 11, 673.

Hofman W. F. \& Ehrhart I. C. (1981) Effects of Methylprednisolone on fatty acid induced oedema in the do lung. fournal of Trauma 21, 878-82.

Jacob H. S., Craddock P. R., Hamerschmidt D. E. \& Moldow C. F. (1980) Complement-induced granulocyt aggregation. New England fournal of Medicine 302, 789-94.

Janoff A., White R., Carp H. et al. (1979) Lung injury induced by leukocytic proteases. American fournal oftz Pathology 97, 111-35.

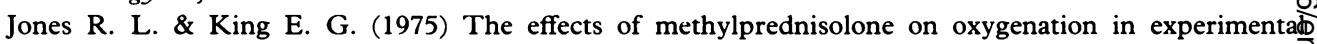
hypoxaemic respiratory failure. Fournal of Trauma 15, 297-303.

Kaplow L. S. \& Goffinet J. A. (1968) Profound neutropenia during the early phase of hemodialysis. fournal of the American Medical Association 203, 1135-7.

Kreis W. R., Lindenauer S. M. \& Dent T. L. (1973) Corticosteroids in experimental fat embolisation. fourna $\mathcal{\varphi}$ of Surgical Research 14, 238-46.

Lucas C. E. \& Ledgerwood A. M. (1981) Pulmonary response of massive steroids in seriously injured patients. Annals of Surgery 194, 256-61.

Lucas C. E. \& Ledgerwood A. M. (1984) The cardiopulmonary response to massive doses of steroids irod patients with septic shock. Archives of Surgery 119, 537-41.

McDonald J. A., Banks B. J., Rosenberg D. M. et al. (1979) Destruction of a major extracellular adhesive् glycoprotein (fibronectin) of human fibroblasts by neutral proteases from polymorphonuclear leukogte granules. Laboratory Investigation 40, 350-7.

Modell J. H., Graves S. A. \& Ketover A. (1976) Clinical course of 91 consecutive near-drowning victing Chest 70, 231-38.

Moylan J. A. \& Chan C. K. (1978) Inhalation injury-an increasing problem. Annals of Surgery 188, 34-7气ू

Rinaldo J. E. \& Rogers R. M. (1982) Adult Respiratory Distress Syndrome. New England fournal of Medicin尺 306, 900-09.

Rinehart J. J., Balcerzak S. P., Sagone A. L. et al. (1974) Effect of corticosteroids on human monocyte

function. Fournal of Clinical Investigation 54, 1337.
Scadding J. G. \& Cumming G. (eds) (1981) Scientific Foundations of Respiratory Medicine. London. Heinemann.

Schonfield S. A., Ploysongsang Y., Dilisio R. et al. (1983) Fat embolism prophlaxis with corticosteroids $\frac{3}{3}$

Annals of Internal Medicine 99, 433-43.
Shephard G. H., Ferguson J. L. \& Foster J. H. (1969) Pulmonary contusion. Annals of Thoracic Surgery $7 \frac{\overline{3}}{3}$ 110.

Sibbald W. J., Anderson R. R., Reid B. et al. (1981) Alveolar-capillary permeability in human septic ARDS effect of high dose corticosteroid therapy. Chest 79, 133-42.

Skormit W. A. \& Dressler D. P. (1974) Effect of short-term steroid therapy on lung bacterial clearance ands survival in rats. Annals of Surgery 179, 415-21.

Sladen A. \& Zauder H. L. (1971) Methylprednisolone therapy for pulmonary oedema following near drowning. Fournal of the American Medical Association 215, 1793-5.

Stoltenberg J. J. \& Gustilo R. B. (1979) The use of methylprednisolone and hypertonic glucose in thల్ prophylaxis of fat embolism syndrome. Clinical Orthopaedics and Radiology Research 143, 211-21.

Svennevig J. L., Bugge-Asperheim B., Bjorga S. et al. (1980) Methylprednisolone in the treatment of lungo contusion following blunt chest trauma. Scandinavian fournal of Thoracic and Cardiovascular Surgery 14 301-5.

Trinkle J. K., Furman R. W., Hinshaw M. A. et al. (1973) Pulmonary contusion-pathogensis and effec of various resuscitative measures. Annals of Thoracic Surgery 16, 568. 
Trinkle J. K., Richardson J. D., Frantz J. L. et al. (1975) Management of flail chest without mechanical ventilation. Annals of Thoracic Surgery 19, 355-63.

Welch G. W. (1977) The use of steroids in inhalation injury. Surgery, Gynecology and Obstetrics 145, 539-44.

Wolfe J. E., Bore R. C. \& Ruth W. E. (1977) Effects of corticosteroids in the treatment of patients with gastric aspiration. American fournal of Medicine 63, 719-22.

Yielding K. L. \& Tomkins G. M. (1959) Inhibition of the enzymatic oxidation of $\mathrm{DPNH}_{3}$ by steroid hormones. Proceedings of the National Academy of Sciences of the USA 45, 1730.

Received 3 September 1984; accepted for publication 2 October 1984 